\author{
Владимир Иванов \\ - Полоцкий государственный университет \\ - e-mail: ivprem@tut.by \\ - ORCID: 0000-0002-4621-7155
}

\title{
Татьяна Вигерина
}

- Полоцкий государственный университет

- e-mail: t.vigerina@psu.by

- ORCID: 0000-0002-8862-5456

ТЕХНИЧЕСКАЯ ВОЗМОЖНОСТЬ И ЭКОНОМИЧЕСКАЯ ЦЕЛЕСООБРАЗНОСТЬ РЕМОНТА АВТОМОБИЛЬНЫХ АГРЕГАТОВ С ВОССТАНОВЛЕНИЕМ ИЗНОШЕННЫХ ДЕТАЛЕЙ

\author{
TECHNICAL OPPORTUNITY AND ECONOMIC EXPEDIENCY \\ OF CAR REPAIR UNITS WITH RESTORATION OF WASTE PARTS
}

\section{Abstract}

- Goal - identification of conditions for the economic feasibility of repairing units with the restoration of parts in comparison with the repair based on the use of new parts.

- Research - techno-economic methods were used, taking into account the changing cost items for technological operations of repairing automobile units in various versions. The limitation was the provision of after-repair running hours of repaired units, not inferior to the standard operating time of new units.

- Score/results - the review shows the conditions under which the main quality indicators in the form of wear resistance and fatigue strength of the restored parts, which determine their durability, are not inferior to the development to the limit state of new parts.

- Originality/value - the cost of restoring individual parts during the repair of units is $8-60 \%$ of the price of new products. The conditions of concentration of production with an increase in its volumes are given, which reduces the complexity of the restoration of parts up to two times.

| Key words: repair, assemblies, restoration, parts, long-eternity, economic feasibility. 


\section{1. Введение}

Система содержания автомобильного парка при эксплуатации в работоспособном состоянии состоит из воздействий двух видов: технического обслуживания и ремонта [Tekhnicheskoe obsluzhivanie...]. Воздействия первого вида направлены на уменьшение интенсивности разрушительных процессов по мере использования автомобилей своевременным выявлением и экономически эффективным предупреждением неисправностей в плановом порядке. Неисправности выявляют диагностированием и предупреждают за счет проведения уборочно-моечных, крепежно-регулировочных и смазочно-заправочных работ. Воздействия второго вида выполняются по потребности и включают устранение неисправностей и восстановление ресурса автомобилей путем замены их отказавших частей на исправные. Наиболее сложным видом ремонта является капитальный ремонт, при котором устраняются любые неисправности с полным восстановлением ресурса. В настоящее время капитальный ремонт техники сводится к ремонту агрегатов и заключается в экономически эффективном восстановлении их надежности в результате наиболее полного использования остаточной долговечности деталей [Vosstanovlenie i uprochnenie...].

Современный бизнес с целью извлечения максимальной прибыли предлагает, во-первых, достигшую предельного состояния технику не ремонтировать, а заменять новыми машинами. И, во-вторых, если он и признает необходимость ремонта, то рекомендует выполнять его с заменой изношенных деталей дорогими новыми деталями в виде запасных частей. Однако, ремонт машин объективно необходим, он позволяет использовать их остаточную долговечность, заложенную при изготовлении. Ремонтируют не только транспортные средства, технологическое оборудование и сельскохозяйственную технику, ремонтируют также тепловозы, самолеты и другие машины. Опыт ремонта самолетов, судов и тепловозов, ремонта автомобилей и двигателей силами заводов-изготовителей свидетельствуют о возможности достижения послеремонтной наработки объектов не меньше, чем у новых изделий, при затратах, не превышающих 60\% затрат на их производство. Практика показывает, что научно обоснованные процессы и организация ремонта машин позволяют достичь нормативной наработки техники, а в отдельных случаях и превзойти наработку новых изделий. 
Восстановление деталей - технологический процесс возвращения им материала вместо изношенного и (или) доведения до нормативных значений изменившихся геометрических параметров и эксплуатационных свойств. К геометрическим параметрам детали относят взаимное расположение, форму, размеры и шероховатость рабочих поверхностей, а к основным эксплуатационным свойствам - износостойкость трущихся поверхностей, усталостную прочность, жесткость и герметичность детали, ее массу и распределение массы относительно осей вращения и инерции [Vosstanovlenie i uprochnenie...].

Восстановление деталей позволяет использовать их материал, форму и остаточную долговечность, что сокращает потребление запасных частей, живого труда, энергии и материалов, а также способствует охране окружающей среды (масса отходов при восстановлении деталей в 20 раз меньшая, чем при их изготовлении [Lyalyakin, 2004]). Только за счет исключения металлургического процесса при восстановлении одной тонны стальных деталей экономят 180 кВт-ч электроэнергии, 0,8 т угля, 0,8 т известняка и 175 м $^{3}$ природного газа [Vosstanovlenie i uprochnenie...]. Таким образом, использование восстановленных деталей при ремонте агрегатов является актуальным. эффективным и ресурсосберегающим мероприятием.

\section{2. Цель}

Обосновать техническую возможность и экономическую целесообразность ремонта автомобильных агрегатов с применением восстановленных деталей.

\section{3. Методология исследования}

Использовались технико-экономические методы обоснования технических решений, основанные на учете количественно изменяющихся статей затрат на технологические операции ремонта автомобильных агрегатов в различных вариантах. Ограничениями решений являлось обеспечение нормативной послеремонтной наработки отремонтированных агрегатов, обусловленной наработкой составляющих деталей. В качестве объекта исследования рассматривались автомобильные агрегаты: двигатели ведущие 
мосты и коробки передач. Затраты на ремонт отдельного агрегата 3 p.a срав-

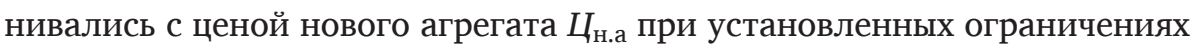

$$
\begin{gathered}
3_{\text {p.a }}=3_{\text {р.-о.р }}+3_{\text {д.р }}+3_{\text {в.д }}+3_{\text {з.ч }}+3_{\text {сб.а }}+3_{\text {обк.а }}<Ц_{\text {н.а }}, \\
\text { при } L_{\text {р.а }} \geq L_{\text {н.а }},
\end{gathered}
$$

где:

$3_{\text {p.-о.p }}$ - затраты на разборочно-очистные работы (руб.),

$3_{\text {д.р }}$ - затраты на дефектацию деталей (руб.),

$3_{\text {в.д }}$ - затраты, связанные с восстановлением деталей (руб.),

$3_{3 . ч}$ - затраты на приобретение деталей обязательной замены (прокладок,

сальников, подшипников качения и подобных) (руб.),

$3_{\text {сб.а }}$ - затраты на сборку агрегата (руб.),

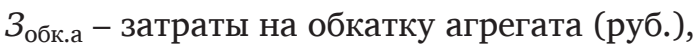

$L_{\text {p.a }}$ - наработка отремонтированного агрегата (тыс. км),

$L_{\text {н.а }}$ - нормативная наработка нового агрегата (тыс. км).

Ограничения, приведенные в зависимости (1), устанавливают тот факт, что наработка отремонтированного агрегата (пробега до предельного состояния) не должна уступать нормативной наработке нового изделия. С этой целью значения геометрических параметров агрегатов и деталей, а также эксплуатационных свойств деталей должны быть доведены до требований конструкторской документации завода-изготовителя. Для агрегатов - это значения замыкающих размеров в соединениях, а для деталей, кроме размерных параметров, - износостойкость трущихся поверхностей, усталостная прочность, жесткость и герметичность деталей, масса деталей, движущихся при работе поступательно, и распределение массы относительно осей вращения и инерции вращающихся деталей.

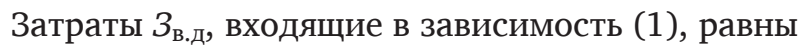

$$
3_{\text {в.д }}=\sum_{1}^{n_{\text {д }}} M+\sum_{1}^{n_{\text {д }}} \sum_{1}^{n_{\mathrm{o}}} T_{\text {ш. }-\mathrm{\kappa}}\left[\frac{C_{\mathrm{ч}}\left(1+k_{\text {д.з.П }}\right)}{60}+3_{\text {о.ч }}+\frac{E_{\mathrm{H}} K_{\text {об }}}{\Phi_{\text {д.о }}}\right] \text {, }
$$

где:

$n_{\text {д }}$ - порядковые номера восстанавливаемых деталей,

$n_{\text {o }}$ - порядковые номера операций процесса восстановление детали, $M=H \cdot u-$ стоимость материалов на восстановительные покрытия (руб.), $H \cdot$ - норма расхода материала (кг), 
ч - цена единицы массы материала (руб./кг),

$T_{\text {ш.-к }}$ - штучно-калькуляционное время на операцию (мин.),

$C_{\text {ч }}$ - тарифная часовая ставка (руб./ч),

$k_{\text {д.з.п }}-$ коэффициент, учитывающий дополнительную заработную плату рабочего,

$3_{\text {о.ч }}$ - часовые затраты, связанные с работой оборудования, включая затраты на энергию (руб./ч),

$E_{\mathrm{H}}-$ нормативный коэффициент эффективности капитальных вложений, $K_{\text {об. }}$ - капитальные вложения в оборудование, отнесенные к одному году (руб./год),

$\Phi_{\text {д.о }}$ - действительный годовой фонд времени работы оборудования (ч/год).

Затраты на ремонт агрегата с использованием новых деталей отличаются от соответствующего показателя при ремонте агрегата с восстановлением деталей (1) заменой стоимости восстановленных деталей ценой приобретенных новых деталей в виде запасных частей Следует отметить. что стоимость всех деталей агрегата, приобретенных как запасные части, превышает в 1,5-2 раза цену самого агрегата.

Рассматривались объемы ремонта агрегатов 1-10 тыс./год.

\section{4. Результаты исследований}

Наибольшую часть экономического эффекта ремонту машин дает восстановление деталей. Производство по восстановлению деталей потребляет трудовые ресурсы, материалы и энергию, необходимые для нанесения покрытий, термической и механической обработки заготовок. Оптимизация расхода этих ресурсов за счет наилучшего их использования при своевременном выполнении производственных заданий и обеспечении нормативных показателей качества и составляет предмет организации производства.

Технико-экономическая целесообразность восстановления деталей кроется в самой природе этого производства. Восстанавливаемые детали утратили работоспособность чаще всего из-за незначительного износа небольшого числа поверхностей (потеря массы деталей при этом составляет до 0,3\%). При восстановлении деталей обрабатывают только около 25\% числа поверхностей, обрабатываемых при их изготовлении. Затраты на материалы при изготовлении деталей составляют 30-40\% общих затрат, 
а при их восстановлении 6-7\% от себестоимости соответствующих процессов. Если эти затраты сопоставить непосредственно, то окажется, что материальные затраты при восстановлении деталей составят лишь 3\% от соответствующих затрат при их изготовлении. Создание ремонтных заготовок пластическим деформирование материала [Ivanov, 2012], электромеханической обработкой или обработкой под ремонтные размеры вообще не требует расхода материалов.

Затраты на восстановление деталей зависят от количества и видов устраняемых повреждений. При первом обращении на восстановление, как правило, обходятся без трудоемкого нанесения восстановительных покрытий, поэтому стоимость восстановления минимальная (таблица 1). Последующее обращение, связанное с нанесением таких покрытий, в 1,5-2 раза увеличивает соответствующие затраты.

Таблица 1. Отношение затрат $3_{\text {в.д }}$ на восстановление основных деталей двигателей к цене новых деталей Цн.д

\begin{tabular}{|c|c|c|}
\hline Деталь & Основные восстановительные операции & $3_{\text {В.д }} / Ц_{\text {H.A }}$ \\
\hline \multirow{2}{*}{$\begin{array}{l}\text { Блок } \\
\text { цилиндров }\end{array}$} & $\begin{array}{l}\text { Развертывание отверстий под толкатели, } \\
\text { шлифование стыков крышек коренных опор, } \\
\text { хонингование опор }\end{array}$ & $0,20-0,30$ \\
\hline & $\begin{array}{l}\text { Развертывание отверстий под толкатели, наплавка } \\
\text { (напыление) и растачивание коренных опор }\end{array}$ & $0,30-0,50$ \\
\hline $\begin{array}{l}\text { Головка } \\
\text { цилиндров }\end{array}$ & Замена втулок клапанов, их развертывание & $0,15-0,20$ \\
\hline \multirow{2}{*}{$\begin{array}{l}\text { Гильза } \\
\text { цилиндра }\end{array}$} & $\begin{array}{l}\text { Растачивание и хонингование под ремонтный } \\
\text { размер }\end{array}$ & $0,10-0,15$ \\
\hline & $\begin{array}{l}\text { Установка листовой дополнительной ремонтной } \\
\text { детали, хонингование под номинальный размер }\end{array}$ & $0,25-0,30$ \\
\hline Поршень & $\begin{array}{l}\text { Шлифование юбки, развертывание отверстия под } \\
\text { поршневой палец, нанесение оловянного покрытия }\end{array}$ & $0,10-0,30$ \\
\hline \multirow{2}{*}{$\begin{array}{l}\text { Поршневой } \\
\text { палец }\end{array}$} & Термопластическая раздача, шлифование & $0,20-0,25$ \\
\hline & Хромирование, шлифование & $0,30-0,45$ \\
\hline Шатун & $\begin{array}{l}\text { Замена втулки, железнение поверхности нижней } \\
\text { головки, обработка резанием поверхностей } \\
\text { отверстий }\end{array}$ & $0,40-0,60$ \\
\hline
\end{tabular}




\begin{tabular}{|c|c|c|}
\hline Деталь & Основные восстановительные операции & $З_{\text {B.A }} / Ц_{\text {H.A }}$ \\
\hline \multirow[b]{2}{*}{ Коленчатый вал } & $\begin{array}{l}\text { Шлифование и полирование шеек } \\
\text { под ремонтные размеры }\end{array}$ & $0,08-0,15$ \\
\hline & $\begin{array}{l}\text { Наплавка (напыление) шеек, их точение, } \\
\text { шлифование и полирование под номинальные } \\
\text { размеры }\end{array}$ & $0,35-0,50$ \\
\hline $\begin{array}{l}\text { Вкладыши } \\
\text { коленчатого } \\
\text { вала }\end{array}$ & $\begin{array}{l}\text { Растачивание под предыдущий ремонтный } \\
\text { (номинальный) размер }\end{array}$ & $0,10-0,15$ \\
\hline \multirow{2}{*}{$\begin{array}{l}\text { Распредели- } \\
\text { тельный вал }\end{array}$} & $\begin{array}{l}\text { Шлифование шеек под ремонтные размеры } \\
\text { и кулачков «как чисто» }\end{array}$ & $0,08-0,12$ \\
\hline & $\begin{array}{l}\text { Наплавка шеек и их шлифование под } \\
\text { номинальные размеры, газопламенная } \\
\text { наплавка кулачков и их шлифование }\end{array}$ & $0,35-0,45$ \\
\hline
\end{tabular}

Источник: собственные исследования.

Современное состояние науки и практики позволяет повысить наработку восстановленных деталей до нормативного значения. Действительно, нанесение покрытий при восстановлении трущихся поверхностей деталей с включением в их материал необходимых элементов подобно химико-термической обработке поверхностных слоев, связано с образованием материала нового химического, структурного и фазового состава, отличного от материала основы. Насыщение поверхностных слоев, например, углеродом, азотом, бором или их сочетанием, с последующими закалкой и отпуском приводят к образованию упрочняющих фаз с наперед прогнозируемыми свойствами [Vigerina, 2013; Ivanov, 2015]. Этому способствует предварительное согласование состава исходного материала покрытий с фазовым составом образуемого покрытия (карбидного, нитридного или другого вида). Полученная гетерогенная структура материала (типа Г. Шарпи) в этом случае, состоит из твердых зерен карбидов, нитридов или других соединений, равномерно распределенных в упругопластической матрице, при этом поверхностные слои трущихся материалов обладают меньшей прочностью, чем нижележащие слои (правило положительного градиента) и не наклепываются при трении [Bogdanovich, 2011].

Основное условие сохранения и повышения усталостной прочности покрытий, нанесенных при восстановлении шеек валов, заключается в создании, как в наплавленном металле, так и в зоне термического влияния 
сжимающих напряжений. Существующие способы наплавки не обеспечивают выполнение этого условия, что приводит к снижению усталостной прочности валов, восстановленных с ее использованием, на 30-40\%. Отрицательное влияние на сопротивление усталости оказывают остаточные растягивающие напряжения, которые вызываются неоднородностью пластического деформирования, различием температурных коэффициентов линейного расширения основного и наплавленного металлов, структурными превращениями в наплавленном металле и зоне термического влияния. Результатом возникновения таких напряжений являются низкая прочность и малая пластичность слоя, образующегося при наплавке на границе основного и наплавленного металлов. Поэтому для повышения усталостной прочности валов в технологический процесс их восстановления рекомендуется вводить операции поверхностного пластического деформирования, способствующие уменьшению градиента структурного перехода между основным материалом и материалом наплавляемого покрытия с поиском оптимальных режимов нанесения покрытия, его механической и термической обработки.

Восстановление жесткости пружин и торсионов до нормативных значений заключается в повышении модуля упругости материала путем его объемного пластического деформирования. Деформированию подвергают объем детали, в котором действуют основные рабочие напряжения (нормальные и касательные) при работе этой детали. С целью восстановления жесткости применяют механическую, химико-термическую и термомеханическую обработку. Тепловые и химические воздействия способствуют распространению структурных превращений вглубь материала восстанавливаемого элемента. Основные виды механической обработки заготовок при восстановлении жесткости: дробеструйная обработка, обкатывание и ультразвуковая обработка.

Непроницаемость стенок корпусных деталей (герметичность) достаточно легко обеспечивают пропиткой твердеющими составами, сваркой, пайкой или приклеиванием пластин.

Требования к замыкающим размерам в соединениях агрегатов одинаковы как при изготовлении, так и при ремонте агрегатов, они обеспечиваются одинаковыми способами, оборудованием и инструментами.

Трудовые затраты при обработке резанием единицы поверхности при восстановлении деталей превышают в 3-40 раз соответствующие затраты при изготовлении деталей. Этот факт объясняется низкой концентрацией 
мелкосерийного типа производства, использованием универсального производства, частыми его переналадками, малыми партиями восстановления.

Низкая цена, высокая производительность и достаточное качество восстановления деталей достигаются при использовании специального оборудования. Это оборудование позволяет получить заданную точность обработки (например, 5-6 квалитетов при обработке шеек валов и 6-7 квалитетов при обработке отверстий) и, как следствие, достичь нормативного ресурса деталей. Специальное оборудование создают с применением последних достижений теории и практики ремонта, его выпускают небольшими партиями, поэтому оно дорогое. Для эффективного использования этого оборудования необходима его полная загрузка, которая достигается увеличением объемов восстановительного производства путем его концентрации и специализации.

Концентрация ремонтного производства по восстановлению деталей выражается увеличением объемов ремонтных работ на одном предприятии за счет увеличения площади обслуживаемого региона, а, следовательно, количества автомобилей в нем. При этом налаживают отношения между владельцами ремонтируемой техники одного типа в пределах района, области или республики и ремонтным предприятием. На это предприятие собирают и доставляют изношенные изделия и организуют их ремонт (восстановление). Концентрация производства связана с увеличением затрат на перевозку ремонтного фонда и товарной продукции.

Специализация производства - это закрепление за каждым производственным подразделением (предприятием, цехом, участком, рабочим местом) ограниченной номенклатуры изделий или видов работ. При этом повышается упорядоченность системы планирования, уменьшается число видов процессов, оборудования и оснастки, сокращается цикл производства, снижаются затраты на единицу продукции. Все это способствует внедрению высшей формы организации - поточного производства. Полная загрузка крупносерийного или массового производства, оснащенного специальным оборудованием, с поточной формой его организации позволяет получить экономический эффект даже при увеличении транспортных расходов. Наибольшее развитие получила технологическая специализация по сравнению с предметной.

Целесообразность концентрации восстановительного производства в виде увеличения объемов производства и назначения вида восстанавливаемых деталей определяется на основании учета следующих сведений [Kakuevickij, 1988]: 
- соотношения между затратами на создание специализированного производства, оборотного ремонтного фонда и его перевозку, с одной стороны, и снижением себестоимости восстановления деталей от увеличения его объема, с другой стороны;

- соотношения между затратами на организацию восстановления деталей заданной номенклатуры и на их производство на заводе-изготовителе.

Допустимое расстояние перевозки деталей на восстановление $S$ (км) определяется из выражения

$$
S \leq \frac{Ц_{\text {н.д }}-3_{\text {в.д }}}{T G_{\text {д }}},
$$

где:

$Ц_{\text {н.д }}$ - цена новой детали (руб.),

Т - тариф на перевозку детали (руб./кг·км),

$G_{\text {д }}-$ вес детали (кг).

Выражение (3) определяет расстояние перевозки восстанавливаемых деталей, при котором экономический эффект от снижения стоимости их восстановления превышает дополнительные затраты на расширение восстановительного производства. Источники экономического эффекта заключены в применении более совершенной организации и технологии, что приводит к снижению себестоимости восстановления и повышению долговечности деталей.

Организация восстановления деталей целесообразна в том случае, когда масштабы работ в рассматриваемом регионе достаточны для создания крупносерийного или массового производства. Организация восстановления деталей оправдана при условии, если затраты на использование детали не будут превышать затрат, связанных с изготовлением и эксплуатацией новой детали.

Увеличение объемов восстановления расширяет рациональную область охвата потребителей. Это приводит к снижению трудоемкости деталей и повышению качества восстановления деталей по сравнению с уровнем качества, достигнутым на небольших предприятиях. Трудоемкость восстановления деталей при возрастании объемов ремонта агрегатов от 1 до 10 тыс. в год уменьшается примерно в два раза (рисунок). Объемы восстановления деталей тем выше, чем больше машин в регионе и их годовая наработка. 
Значительные объемы восстановления легче обеспечить для многочисленных недолговечных деталей, характеризующихся большим весом.

Рисунок 1. Влияние объемов N ремонта агрегатов автомобилей грузоподъемностью

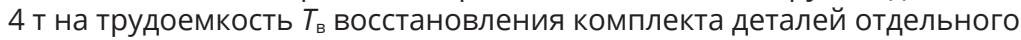
агрегата: двигателя, заднего моста, коробки передач

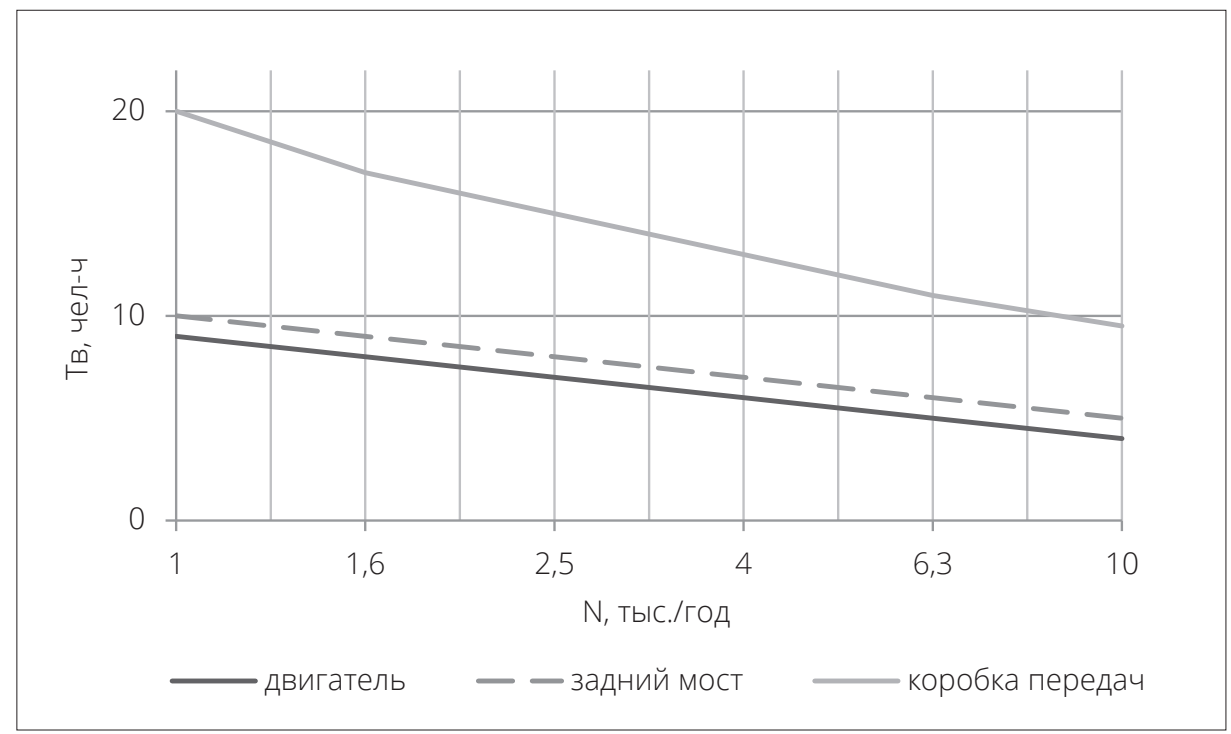

Источник: собственные исследования.

Увеличение веса восстанавливаемых деталей снижает величину целесообразного расстояния их перевозки. Особенно резкое снижение этого расстояния наблюдается для деталей большой массы, себестоимость восстановления которых небольшая.

Большие эксплуатационные затраты, вызванные малой долговечностью деталей, восстановленных на небольших участках восстановления деталей, допускают увеличение расстояния перевозки деталей на их промышленное восстановление.

Восстановлению деталей в условиях высокой концентрации производства подлежат наиболее изношенные и поврежденные дефицитные детали распространенных моделей машин с высокой плотностью распределения их в рассматриваемом регионе. Потребность этих деталей в эксплуатации и при ремонте техники особенно велика. Наибольшая эффективность достигается при создании специализированного производства по определенной номенклатуре этих деталей. Для этих деталей характерными являются 
значительные затраты на замену их в эксплуатации и малые себестоимость восстановления и стоимость перевозки. Особенно важно организовать качественное восстановление на специализированном производстве корпусных и основных деталей, срок службы которых до предельного состояния или отказа определяет послеремонтные ресурсы агрегатов.

Такие массовые детали, как поршневые пальцы, толкатели, крестовины кардана и дифференциала, муфты и фланцы валов, шатуны, гильзы цилиндров, шкворни, колесные тормозные цилиндры и ряд других допускают экономически обоснованную перевозку их на расстояние 300-500 км. Для таких деталей может быть организовано одно производство по их восстановлению в республике или крупном регионе.

Промышленному восстановлению подлежат и более металлоемкие изделия. Допустимое расстояние перевозки карданных, коленчатых и распределительных валов, вилок и фланцев карданов, валов коробок передач и других деталей меньше примерно в два раза, чем в предыдущем случае. Восстановление их целесообразно организовать в областных регионах. Ряд сборочных единиц, имеющих значительную массу (головки и блоки цилиндров, картеры коробок передач и редукторов), целесообразно восстанавливать на участках только при определенном сочетании повреждений.

Наконец, некоторые детали нерационально восстанавливать централизованно, потому что даже в условиях значительной концентрации производства на специализированных предприятиях невозможно обеспечить себестоимость восстановления, которая не меньше затрат на изготовление детали. На заводе по капитальному ремонту машин следует сохранить восстановление простых деталей, имеющих низкую стоимость изготовления, но в результате изнашивания которых приходится восстанавливать значительную (более $100 \mathrm{~cm}^{2}$ ) рабочую поверхность. Это - валы и оси шестерен масляных насосов, валики и оси педалей, оси блоков шестерен, штоки переключения скоростей, крышки подшипников и др.

В рамках одного ремонтного завода следует выделять участки восстановления деталей, взятых с комплексных участков ремонта отдельных агрегатов. Производительность труда на таких участках в 1,5-1,8 раза выше, а себестоимость на 20-30\% ниже, чем на комплексных. Восстановления деталей организуют, как правило, по типовой или модульной технологии.

В целях подъема престижа ремонтных предприятий на них целесообразно организовать изготовление и новых деталей из приобретенных поковок или отливок. Это сокращает дефицит запасных частей взамен выбракован- 
ных и уменьшает цену ремонта. На ремонтном предприятии, имеющем литейный и кузнечно-штамповочный участки, может быть организован полный цикл изготовления гильз цилиндров из серого износостойкого чугуна и стальных или резиновых уплотнительных колец под них, поршней, шатунов, коленчатых и распределительных валов, маховиков и их зубчатых венцов, шестерен масляного насоса, распределительных шестерен коленчатого и распределительного валов, втулок распределительного вала и направляющих клапанов, корпусов масляного и водяного насосов, маслоотражательных колпачков, дисков сцеплений нажимных и ведомых, рычагов сцепления и других деталей. Ремонтный завод на собственных литейных мощностях может получить отливки поршней, маховиков, нажимных дисков сцеплений, различных дополнительных ремонтных деталей.

\section{5. Заключение}

Обоснована техническая возможность восстановления изношенных деталей с достижением послеремонтной наработки агрегатов, собранных из этих деталей, не уступающих наработке до предельного состояния новых агрегатов. Предложены технические решения по повышению износостойкости и усталостной прочности, обеспечивающие долговечность восстановленных деталей, не уступающей наработке до предельного состояния новых деталей. Показана экономическая целесообразность ремонта автомобильных агрегатов с восстановления изношенных деталей по сравнению с использованием новых запасных частей. Стоимость восстановления отдельных деталей составляет 8-60\% от цены новых изделий. Приведены условия концентрации производства с увеличением его объемов, что уменьшает трудоемкость восстановления деталей до двух раз.

\section{І литература}

Bogdanovich P.N., 2011, Trenie, smazka i iznos v mashinakh, Minsk || Богданович П.Н, 2011, Трение, смазка и износ в машинах, Минск.

Ivanov V.P., 2012, Ustrojstvo dlya poverkhnostnogo plasticheskogo deformirovaniya cilindricheskikh poverkhnostej, "Aficyjny byulleten Nacyyanalnaha centra intelektualnaj 
ulasnasci”, No. 1, s. 1-4 || Иванов В.П., 2012, Устройство для поверхностного пластического деформирования цилиндрических поверхностей, «Афіцыйны бюллетэнь Нацыянальнага цэнтра інтэлектуальнай уласнасці», № 1, с. 1-4. Ivanov V.P., 2015, Obespechenie normativnoj posleremontnoj nadezhnosti kolenchatykh valov, [v:] Innovacii v otrasli narodnogo khozyaistva, kak faktor resheniya socialno-ekonomicheskikh problem sovremennosti, red. E. Bodrova et al., Moskva, s. 165-175 || Иванов В.П., 2015, Обеспечение нормативной послеремонтной надежности коленчатых валов, [в:] Инновации в отрасли народного хозяйства, как фактор решения социально-экономических проблем современности, ред. Е. Бодрова и др., Москва, с. 165-175.

Kakuevickij V.A., 1988, Vosstanovlenie detalei avtomobilei na specializirovannykh predpriyatiyakh, Moskva || Какуевицкий В.A., 1988, Восстановление деталей автомобилей на специализированных предприятиях, Москва.

Lyalyakin V.P., 2004, Vosstanovlenie i uprochnenie detalei mashin v agropromyshlennom komplekse Rossii i Belarusi, "Remont, vosstanovlenie, modernizaciya", No. 2, s. c. 2-6 || Лялякин В.П., 2004, Восстановление и упрочнение деталей машин в агропромышленном комплексе России и Беларуси, «Ремонт, восстановление, модернизация», № 2, с. 2-6.

Tekhnicheskoe obsluzhivanie i remont avtomobilnykh transportnykh sredstv. Normy i pravila provedeniya, 2012, Belorusskij nauchno-issledovatelskij institut transporta "Transtekhnika”, Minsk || Техническое обслуживание и ремонт автомобильных транспортных средств. Нормы и правила проведения, 2012, Белорусский научно-исследовательский институт транспорта «Транстехника», Минск.

Vigerina T.V., 2013, Tekhnologiya vosstanovleniya kolenchatykh valov dvigatelei iz vysokoprochnogo chuguna i konstrukcionnoi stali napyleniem, naplavkoi i poverkhnostnym plasticheskim deformirovaniem, avtoreferat dissertacii, Minsk || Вигерина Т.В., 2013, Технология восстановления коленчатьх валов двигателей из высокопрочного чугуна и конструкционной стали напьлением, наплавкой и поверхностным пластическим деформированием, автореферат диссертации, Минск.

Vosstanovlenie i uprochnenie detalej, 2013, red. F.I. Panteleenko, Moskva || Восстановление и упрочнение деталей, 2013, ред. Ф.И. Пантелеенко, Москва. 